\title{
Effect of Viscosity and Temperature on the Microstructure of BBT Thin Films
}

\author{
Gustavo Carneiro da Costa, Alexandre Zirpoli Simões*, Gisele Gasparotto, \\ Maria Apasrecida Zaghette, Biljana Stojanovic, Mario Cilense, José Arana Varela \\ Chemistry Institute, Universidade Estadual Paulista, UNESP \\ 14801-970 Araraquara - SP, Brazil
}

Received: October 18, 2002; Revised: April 13, 2003

\begin{abstract}
Thin films of BBT were deposited on silicate and $\mathrm{Pt} / \mathrm{Ti} / \mathrm{SiO}_{2}(111)$ substrates by spin- coating from the polymeric precursor method (Pechini process). The obtained films were characterized by optical microscopy, X-ray diffraction and atomic force microscopy. The influence of viscosity on the morphology of BBT thin films as well as the influence of temperature on crystallization, morphology and properties of BBT are discussed. Surface roughness and crystallization of these films are strongly dependent on the annealing conditions.
\end{abstract}

Keywords: BBT, thermal treatment, viscosity

\section{Introduction}

In recent years, ferroelectric thin films have attracted much attention for use in nonvolatile applications. High dielectric constant materials are being explored for the next generation of high-density dynamic random-access memory (DRAM) applications because the thickness limit of oxide/nitride is about to be reached. The so-called Aurivillius compounds were discovered in the late $40{ }^{\prime} \mathrm{s}^{1-3}$, and their basic structural and ferroelectric properties were studied in the early 60's ${ }^{4}$. The crystal structure of $\mathrm{BaBi}_{2} \mathrm{Ta}_{2} \mathrm{O}_{9}$, consists of $\mathrm{Bi}_{2} \mathrm{O}_{2}$ layers and perovskite-type $\mathrm{BaTa}_{2} \mathrm{O}_{7}$ units with double $\mathrm{TaO}_{6}$ octahedral layers. The Aurivillius family of bismuth layered structure compounds, which were first reported 50 years ago, can be described by the general formula $\left(\mathrm{Bi}_{2} \mathrm{O}_{2}\right)^{2+}\left(\mathrm{A}_{\mathrm{m}-1} \mathrm{~B}_{\mathrm{m}} \mathrm{O}_{3 \mathrm{~m}+1}\right)^{2-}$, where $\mathrm{A}=\mathrm{Ba}, \mathrm{Pb}, \mathrm{Sr}, \mathrm{Bi}, \mathrm{K}$ or $\mathrm{Na} ; \mathrm{m}=2$, 4, or 5 and $\mathrm{B}=\mathrm{Ti}, \mathrm{Nb}, \mathrm{Ta}^{1-3,5-10}$. Spontaneous polarization in these types of materials is an effect of a combination of both, the displacement of the $\mathrm{B}$ cations and a tilting of the $\mathrm{BO}_{6}$ octaedra ${ }^{6}$. The Curie temperature, Tc, is $210{ }^{\circ} \mathrm{C}$ and $110^{\circ} \mathrm{C}$ for $\mathrm{B}=\mathrm{Nb}$ and $\mathrm{Ta}$, respectively. Either $\mathrm{BaBi}_{2} \mathrm{Nb}_{2} \mathrm{O}_{9}$ or $\mathrm{BaBi}_{2} \mathrm{Ta}_{2} \mathrm{O}_{9}$ exhibits a broad temperature dependent phase transition ${ }^{5}$. These materials may be good candidates for nonvolati1e or volati1e memory applications ${ }^{7,8}$. Currently, $\mathrm{PbZr}_{\mathrm{x}} \mathrm{Ti}_{1-\mathrm{x}} \mathrm{O}_{3}(\mathrm{PZT})$ is considered a most promising material for ferroelectric random access memory

*e-mail: alezipo@yahoo.com

Trabalho apresentado no $1^{\circ}$ Congresso da Sociedade Brasileira em Materiais, Rio de Janeiro, Julho de 2002.
(FRAM) applications. However, one of the major disadvantages in using PZT films for FRAM applications is its high dielectric constant. Additionally, PZT films are known to suffer from significant polarization loss with increasing switching cycles (fatigue) on Pt electrodes. In contrast, bismuth layered structure ferroelectric oxides such as $\mathrm{SrBi}_{2} \mathrm{Ta}_{2} \mathrm{O}_{9}-\mathrm{SrBi}_{2} \mathrm{Nb}_{2} \mathrm{O}_{9}$ solid solutions exhibit a low dielectric constant ( $\sim 300$ at $10 \mathrm{kHz}$ ), almost no fatigue on Pt electrodes, and very low leakage currents $\left(\sim 10^{-8} \mathrm{~A} / \mathrm{cm}^{2}\right.$ at $100 \mathrm{kV} / \mathrm{cm})^{7,8,10}$. On the other hand, the properties of the above named materials are strongly influenced by the preparation method.

The polymeric precursors method, among other chemical methods, is well-known in the area of processing thin films for a number of virtues: easier composition control, better homogeneity, low processing temperature (compatible with Si processing), easier fabrication of large area thin films, and low cost ${ }^{9}$. An intrinsic problem of the solutionbased methods is the large volume change that takes place when the liquid solution transforms into the thin solid inorganic oxide film. This volume change can cause cracking in the film during the pyrolysis and sintering process. In general, the appearance of cracks is lower in thinner films. The main reason for this is that in the thinner coatings the adhesion on the interface film-substrate is higher and lat- 
eral shrinkage of film is suppressed. When the critical value for thickness of films is reached, the cracks can not be avoided. To obtain crack-free films one has to control the characteristic parameters of the solution, such as: viscosity and ionic concentration, substrate-film adhesion, heating conditions, atmosphere, substrate and withdrawal speed. The differences between thermal expansion coefficients of the film and the substrate also have influenced a role in the process of cracking ${ }^{11}$. Moreover, the use of clean room processing is advisable in order to avoid cracks and atmosphere contamination. In general, the choice of substrate depends on the intended application. To investigate the integration of BBT materials in ferroelectric random access memory (FRAM), a platinum coated silicon substrate is used ${ }^{8}$.

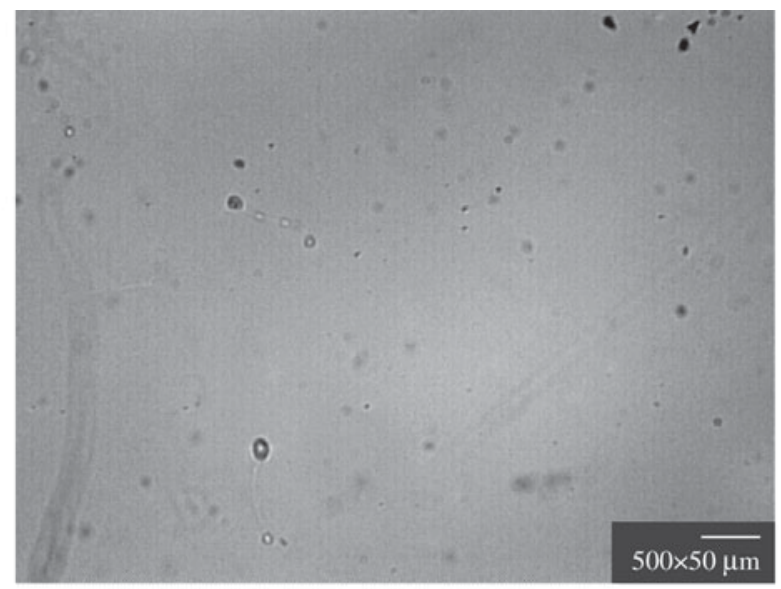

a)

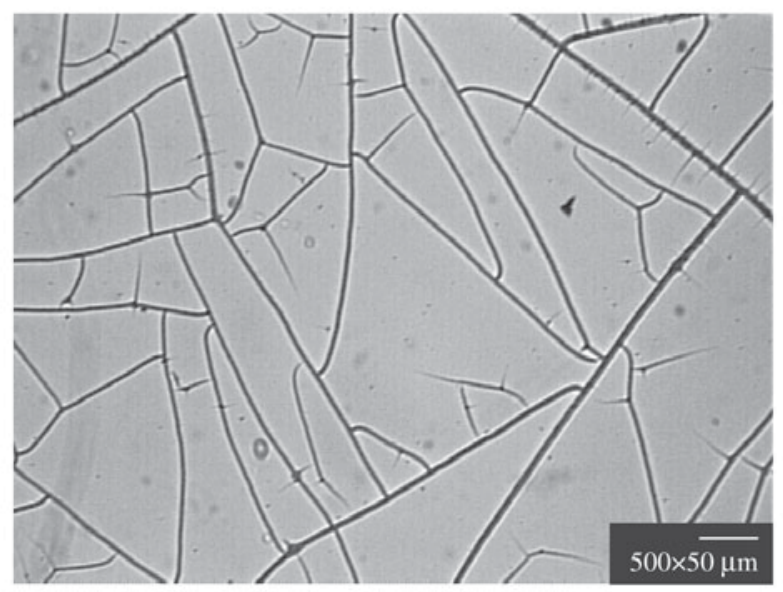

c)
This paper describes the preparation of BBT thin films by the polymeric precursors method (so-called Pechini method) and their structural characterization in terms of phase formation, morphology and chemical composition. The BBT films obtained from polymeric precursors are amorphous and post annealing in oxygen atmosphere is necessary. The main objective of this work was to verify the effect of viscosity and temperature on the microstructure of BBT thin films.

\section{Experimental Procedure}

Barium carbonate $\left(\mathrm{BaCO}_{3}\right.$ - Mallinckrodt - $\left.99.9 \%\right)$, bismuth oxide $\left(\mathrm{Bi}_{2} \mathrm{O}_{3}\right.$ - Baker Analyzed- $\left.99.6 \%\right)$ and tantalum ethoxide $\left(\mathrm{Ta}\left(\mathrm{OC}_{2} \mathrm{H}_{5}\right)_{5}\right.$ - Alpha-aesar - $\left.99.999 \%\right)$ were used

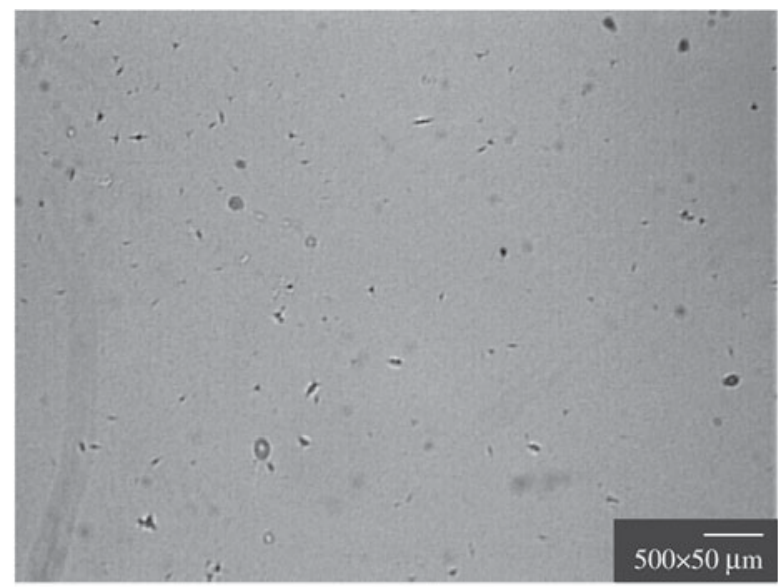

b)

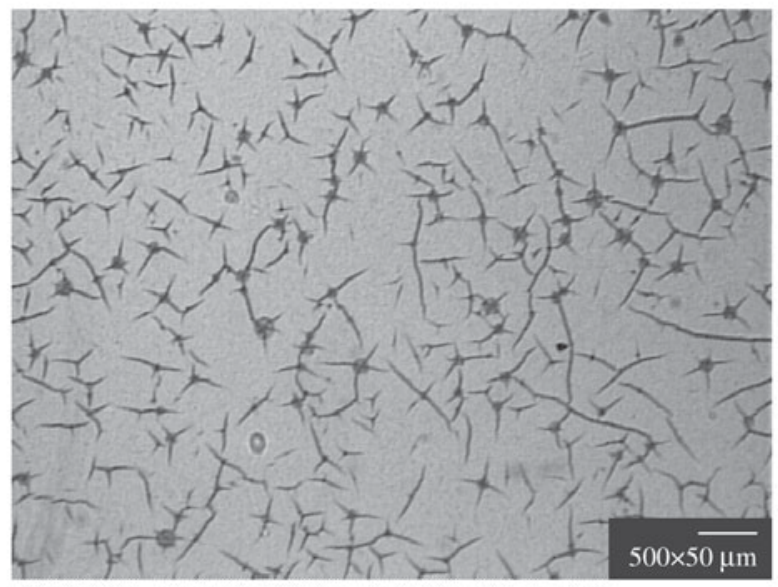

d)

Figure 1. Optical microscopy micrographs (3000x) for BBT thin film annealed at $550{ }^{\circ} \mathrm{C}$ for $1 \mathrm{~h}$ in oxygen atmosphere: (a) $20 \mathrm{cPs}$; (b) $40 \mathrm{cPs}$; (c) $80 \mathrm{cPs}$; (d) $100 \mathrm{cPs}$. 
as purchased without further purification. The precursor solutions of barium, bismuth and tantalum were prepared by adding the raw materials into ethylene glycol and citric acid with heating and stirring at $90{ }^{\circ} \mathrm{C}$. The viscosity of the solution was adjusted from 20 to $100 \mathrm{cPs}$ by addition of water using a Brookfield viscosimeter. In order to investigated the influence of viscosity on the microstructure of BBT thin films, the precursor was deposited on glass substrates with 3 layers and annealed at $550{ }^{\circ} \mathrm{C}$ for $1 \mathrm{~h}$ in oxygen atmosphere. To verify the influence of temperature on the crystallization and microstructure of BBT films, platinum coated silicon was used as a substrate. The 5-layer films were prepared annealing each individual layer. The spinning speed used was $5000 \mathrm{rpm}$ and the films were treated in temperatures ranging from 700 to $800{ }^{\circ} \mathrm{C}$ for $2 \mathrm{~h}$. The heating rate was $1{ }^{\circ} \mathrm{C} / \mathrm{min}$ up to $300{ }^{\circ} \mathrm{C}$ and $5{ }^{\circ} \mathrm{C} / \mathrm{min}$ from $300{ }^{\circ} \mathrm{C}$ to $700-800{ }^{\circ} \mathrm{C}$. Phase analysis of the films was performed at room temperature by $\mathrm{X}$-ray diffraction using a BraggBrentano diffractometer (Rigaku 20-2000) and $\mathrm{CuK} \alpha$ radiation. Atomic force microscopy (AFM - Multi-mode Nanoscope IIIa) was used to obtain a three-dimensional image reconstruction of the sample surface. These images allow for an accurate analysis of the sample surface and the quantification of very important parameters such as grain size and roughness. The thickness of the annealed films was studied using scanning electron microscopy (SEM - Topcon SM-300) observing the transversal section of films. Each value of the thickness obtained by SEM represents an average value of three measurements.

\section{Results and Discussion}

As mentioned above, it is well-known that the control of viscosity, heating condition, thickness and spinning rate, as well as the differences in the thermal expansion coefficients of film and substrate, are very important factors to be considered in the preparation of thin films. In order to investigate the influence of viscosity on the microstructure of BBT thin films, specimens with 20, 40, 80 and $100 \mathrm{cPs}$ were evaluated. The surface characteristics of the films deposited on silicate substrates with 3 layers and annealed at $550{ }^{\circ} \mathrm{C}$ for $1 \mathrm{~h}$ in oxygen atmosphere were analyzed by optical microscopy, Fig. 1. In order to determine the convenient viscosity to obtain crack-free films the three-layered film was used since the deposition of more layers even for low viscosities usually leads to surface defects.

Crack-free thin films were obtained and the topographic morphology was homogeneous for the films deposited with viscosity of $20 \mathrm{cPs}$. On the other hand, for the same conditions of spinning rate and heating rate but for higher viscosities, Fig. 1b-d, various kinds of crack morphologies were observed. For the films deposited with $40 \mathrm{cPs}$, only some islands of microcracks were present (Fig. 1b). The films obtained with viscosity of $80 \mathrm{cPs}$ have the surface covered with long straight lines of cracks (Fig. 1c). Differently, for the films obtained with viscosity of $100 \mathrm{cPs}$, short straight lines of cracks were observed (Fig. 1d). These results suggest that the amount of material deposited on the substrate surface influences the microstructure. This study shows that low viscosities are more convenient for the preparation of BBT films with good morphologic characteristics and free of cracks.

Figure 2 shows the dependence of thickness as a function of viscosity for BBT thin films annealed at $550{ }^{\circ} \mathrm{C}$ for $1 \mathrm{~h}$ in oxygen atmosphere. As discussed previously, for films deposited with viscosities higher than $20 \mathrm{cPs}$, the appear-

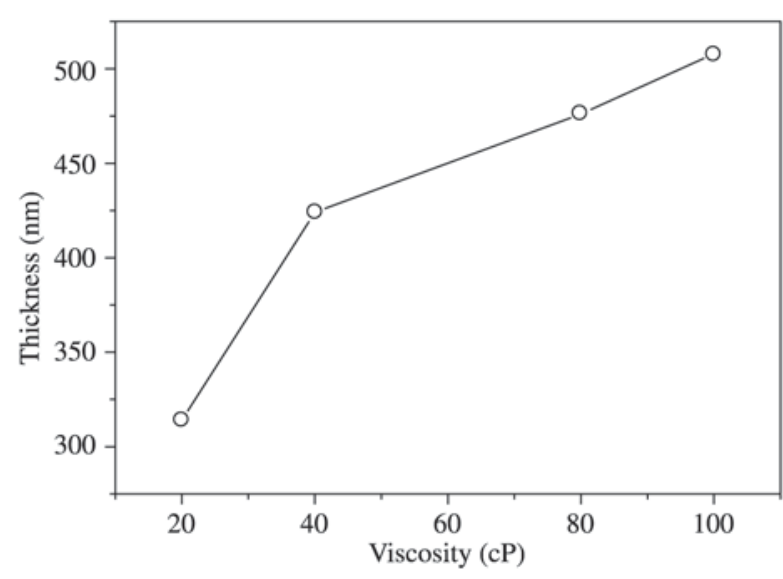

Figure 2. Dependence of thickness as a function of viscosity for BBT thin films annealed at $550^{\circ} \mathrm{C}$ for $1 \mathrm{~h}$ in oxygen atmosphere.

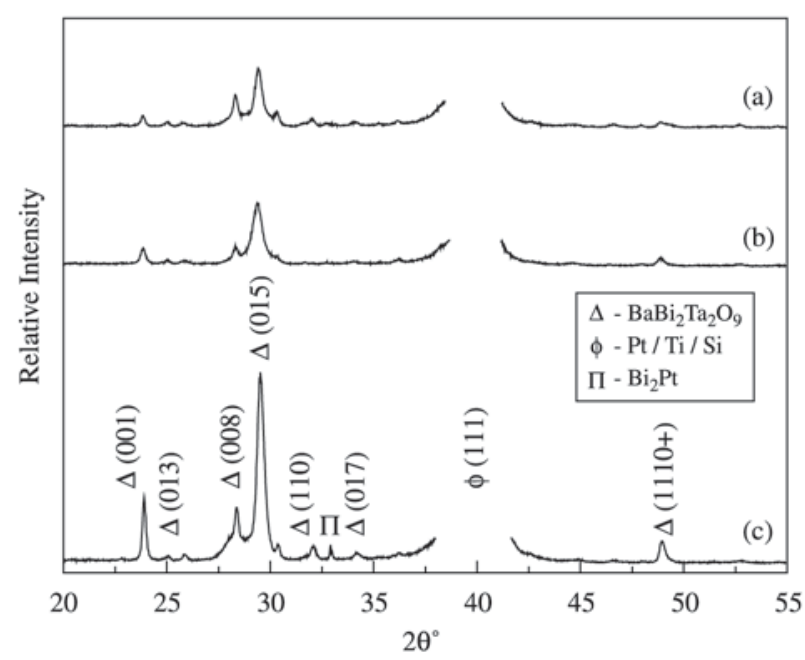

Figure 3. XRD patterns of BBT film annealed in oxygen atmosphere at different temperatures: (a) $700{ }^{\circ} \mathrm{C}$; (b) $750{ }^{\circ} \mathrm{C}$; (c) $800{ }^{\circ} \mathrm{C}$. 
ance of cracks was noticed. This means that the decomposition of organic material in the case of films with higher thickness causes cracks on the surface of substrate. This is not observed for films prepared from solutions with low viscosities because the amount of organic material in the substrate surface is smaller and the appearance of cracks on the film surface was avoided. Bearing in mind that the films prepared with viscosity of $20 \mathrm{cPs}$ showed homogeneous and crack-free surface the influence of temperature on the microstructure of these films was investigated.

It is important to control the thickness of the layer due to its strong influence on the grain size, dielectric and ferroelectric properties. It was observed that for thinner films interfacial "dead layers" could appear at the interface between films and substrate. These layers possess poor dielectric properties, influencing the performance of the device $^{12}$. These "dead layers" are originated from oxygen interdiffusion, chemical reaction, or structural defects at the interfaces and their effect could be suppressed with thickness of films higher than $200 \mathrm{~nm}$. Such thickness could be obtained by multi-layer depositions. To obtain films with thickness higher than $200 \mathrm{~nm}$ it was necessary to deposit 5layer on the platinum-coated silicon substrate.

The X-ray diffraction data for the films with 5 layers deposited on (111) platinum-coated silicon substrates and

Table 1. Thickness, roughness and grain size for BBT thin films deposited on the $\mathrm{Si} / \mathrm{Ti} / \mathrm{Pt}$ (111).

\begin{tabular}{cccc}
\hline $\begin{array}{c}\text { Temperature } \\
\left({ }^{\circ} \mathrm{C}\right)\end{array}$ & $\begin{array}{c}\text { Thickness } \\
(\mathrm{nm})\end{array}$ & $\begin{array}{c}\text { Roughness } \\
(\mathrm{nm})\end{array}$ & $\begin{array}{c}\text { Average Grain } \\
\text { Size }(\mathrm{nm})\end{array}$ \\
\hline 700 & 362 & 10.31 & 87 \\
750 & 305 & 12.34 & 150 \\
800 & 267 & 14.65 & 177 \\
\hline
\end{tabular}

annealed from 700 to $800{ }^{\circ} \mathrm{C}$ for $2 \mathrm{~h}$, are shown in Fig. 3 . The main peaks of the $\mathrm{BaBi}_{2} \mathrm{Ta}_{2} \mathrm{O}_{9}$ crystalline phase were observed after annealing in this temperature range. The characteristic peak for (111) platinum-coated silicon substrates at $2 \theta=40^{\circ}$ is identified in Fig. 3. The increase of temperature improves crystallinity of the BBT phase. The XRD pattern clearly indicates the presence of a small amount of secondary phase $\left(\mathrm{Bi}_{2} \mathrm{Pt}\right)$ at $2 \theta=32.3^{\circ}$ for film treated at $800{ }^{\circ} \mathrm{C}$ for $2 \mathrm{~h}$. This phase is originated from an interface reaction between the platinum and bismuth. The measured pattern evidences that the specimen is polycrystalline.

The average grain size and roughness determined from surface analyses by AFM are shown in Table 1 and in Fig. 4. Due to the higher ionic mobility during the sintering process, the grain growth and densification of the material were observed when the sintering temperature was increased from 700 to $800{ }^{\circ} \mathrm{C}$. Thus, the grain growth is occurring preferentially on the $\mathrm{z}$ direction, perpendicular to the substrate surface and, as a consequence, the roughness of film surface increased when the annealing temperature was enhanced from 700 to $800{ }^{\circ} \mathrm{C}$. Therefore, the distance from the substrate base to the top of the grain increases with the grain growth, promoting an increase of the roughness (Fig. 4).

\section{Conclusions}

The best morphologic characteristics were obtained for BBT films deposited from a solution with viscosity of $20 \mathrm{cPs}$. BBT thin films without preferential orientation and with good crystallinity were obtained on platinum-coated silicon substrates. The roughness increases with the annealing temperature due to the preferential grain growth along the $\mathrm{z}$ direction. The annealing temperature influenced on grain growth due to the higher ionic mobility during the sintering process. Crack-free BBT films without secondary

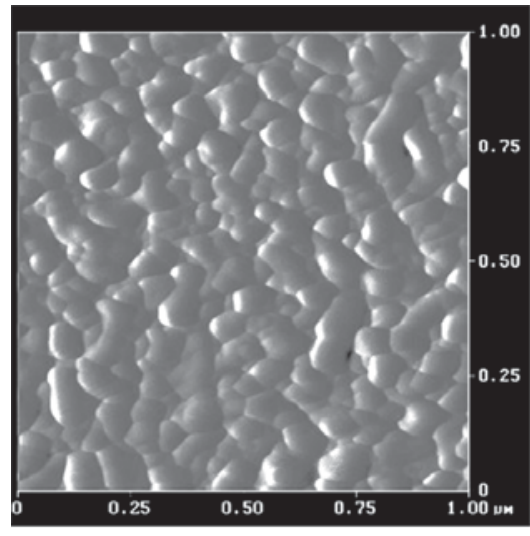

a)

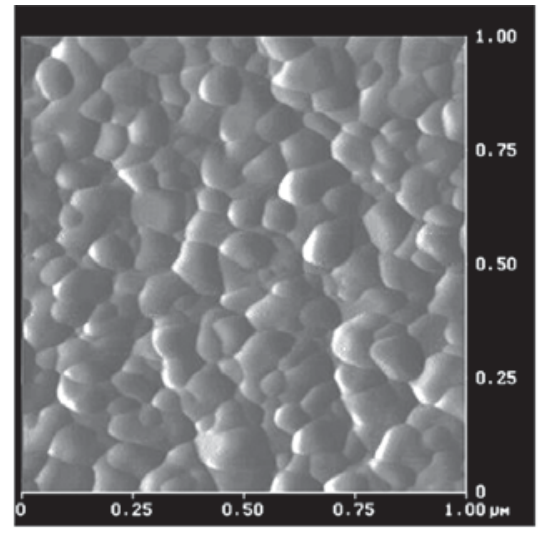

b)

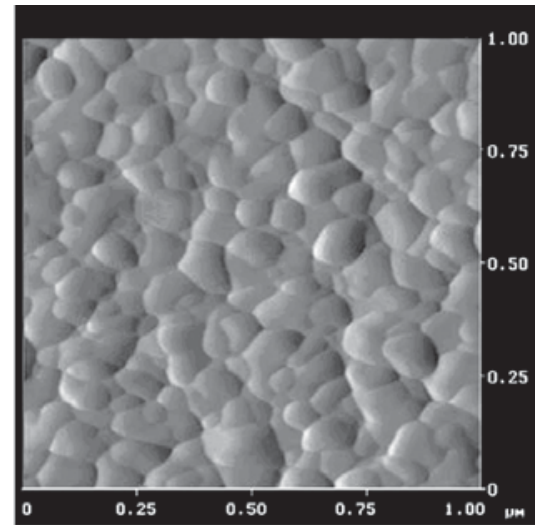

c)

Figure 4. AFM micrographs of BBT film annealed in oxygen atmosphere at different temperatures: (a) $700{ }^{\circ} \mathrm{C}$; (b) $750{ }^{\circ} \mathrm{C}$; (c) $800{ }^{\circ} \mathrm{C}$. 
phases with surface roughness from 10 to $15 \mathrm{~nm}$ can be obtained up to thickness of $400 \mathrm{~nm}$.

\section{Acknowledgements}

The authors acknowledge the Brazilian agencies CNPq, CAPES and FAPESP for financial support of this work.

\section{References}

1. Aurivillius, B. Ark. Kemi, v. 1, p. 463, 1949.

2. Aurivillius, B. Ark. Kemi, v. 1, p. 499, 1949.

3. Aurivillius, B. Ark. Kemi, v. 2, p. 519, 1950.

4. Subbarao, E.C. J. Phys. Chem. Solids, v. 23, p. 665, 1962.

5. Smolenskii, G.A.; Isupov, V.A.; Agranovskaya, A.I. Fiz. Tverd. Tela, v. 3, p. 895, 1961.
6. Wachsmuth, B.; Zshech, E.; Thomas, N.W.; Brodie, S.G.; Gurman, S.J.; Baker, S.; Bayliss, S.C. Phys. Status Solidi A, v. 135 , n. 1, p. $59,1993$.

7. Araujo. C.Paz de, Cuchiaro, J.D.; McMillan, L.D.; Scott, M.C.; Scott, J.F. Nature, v. 374, p. 627, 1995.

8. Foschini, C.R.; Joshi, P.C.; Varela, J.A.; Desu, S.B. J. Mater. Res, v. 14, n. 5, p. 1860, 1999.

9. Paulin Filho, P.I.; Foschini, C.R.; Varela, J.A.; Suchicital, C.T.A. Acta Microscópica, v. 8, Supp. A, 1999.

10. Desu, S.B.; Vijay, D.P. Mater Sci. Eng, v. B32, p. 83, 1995.

11. Brinker, C.J.; Hurd, A.J.; Schunk, P.R.; Frye, G.C.; Asley, C.S. J. Non Cryst. Solids, v. 424, p. 147, 1992.

12. Raymond, M.V.; Smyth, D.M. J. Phys. Chem. Solids, v. 57, p. $1507,1996$. 